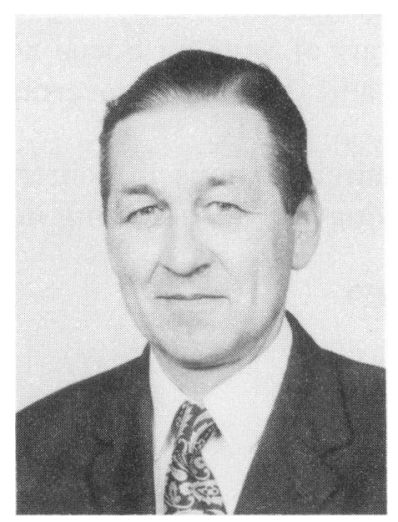

\title{
First International Conference on Emergency Medicine
}

Over the past few years there have been a number of international conferences where emergency medicine was one of the topics considered-conferences on emergency and disaster medicine, or emergency medicine and intensive care.

This is the first conference concerned specifically and solely with emergency medicine, and organised by the four official bodies which lead and direct the speciality in the countries where it has been recognised and accepted: the American College of Emergency Physicians, the Canadian Association of Emergency Physicians, the Australasian College for Emergency Medicine and, in the United Kingdom, the Casualty Surgeons Association.

In devising a programme, the co-operating bodies have had three aims in mind:

(1) To allow delegates to experience the atmosphere of a major international event which is large yet cohesive and purposeful. To this end, there are plenary sessions each morning, with a theme for the day, and contributors from the four co-operating bodies. Other plenary sessions are planned for Tuesday and Friday afternoons.

(2) To allow as many delegates as possible to participate in comment, discussion and criticism, and to allow delegates to get to know the members of a sub-group of the conference in a more intimate way than is possible in plenary sessions. We hope to achieve this aim through six workshops which will be held in the second half of each morning.

(3) To allow a wide spectrum of emergency physicians to present their research to an international audience. This should be achieved in the Free Paper sessions, where 92 papers will be presented.

Meeting new friends is as important as attending academic sessions. So we hope delegates will be able to participate in the different plays, concerts, boat trips etc. of the social programme. The highlight of this is the banquet. This is to be held in London's 
historic Guild Hall, where we will have as our guests the presidents of the Roya Colleges of Physicians and Surgeons, and our chief guest will be the Right Honorable⿳亠丷厂巾 Norman Fowler MP, the Secretary of State for Social Services in the United Kingdom? $\mathrm{He}$ is a member of the cabinet and the Senior government minister involved with all? matters relating to health.

I hope this explanation of our intentions in constructing the programme will beo helpful in understanding, enjoying and participating in all aspects of the conference.

WILLIAM H. RUTHERFORD

Chairman 